\title{
Understanding soil and plant interaction by combining ground-based quantitative electromagnetic induction and airborne hyperspectral data
}

\section{Christian von Hebel ${ }^{1,3}$, Maria Matveeva ${ }^{2}$, Elizabeth Verweij ${ }^{1}$, Patrick Rademske ${ }^{2}$, Manuela Sarah Kaufmann ${ }^{1,3}$, Cosimo Brogi ${ }^{1}$, Harry Vereecken ${ }^{1,3}$, Uwe Rascher ${ }^{2}$, Jan van der Kruk ${ }^{1,3}$}

${ }^{1}$ Forschungszentrum Jülich, Institute of Bio- and Geoscience, Agrosphere, IBG-3

${ }^{2}$ Forschungszentrum Jülich, Institute of Bio- and Geoscience, Plant science, IBG-2

${ }^{3}$ Centre for High-Performance Scientific Computing in Terrestrial Systems, TerrSys

Corresponding author: Christian von Hebel (c.von.hebel@fz-juelich.de)

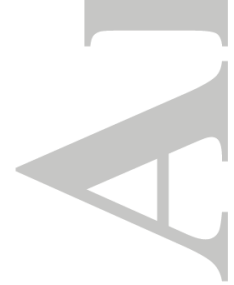

\section{Key Points:}

- Soil structures at depth obtained by quantitative 3D electromagnetic induction data inversions not by apparent electrical conductivity maps

- Deeper subsoil characteristics correlate with airborne sun-induced fluorescence data indicating soil moisture effects on plant performance

- Quantitative inverted electrical conductivity model together with plant data help to inform and improve soil-vegetation-atmosphere models

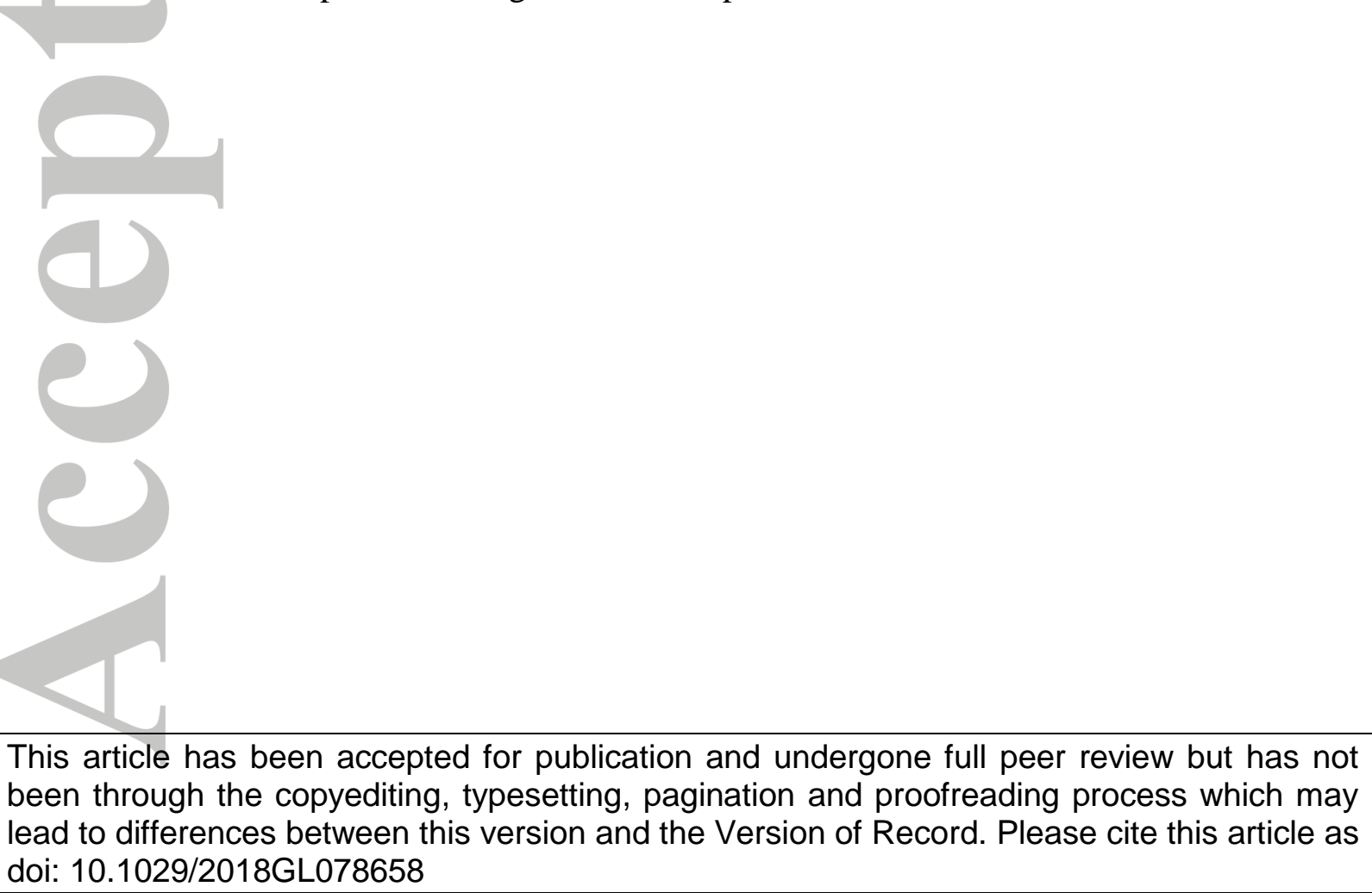

(C) 2018 American Geophysical Union. All rights reserved. 


\begin{abstract}
For the first time, we combine depth-specific soil information obtained from the quantitative inversion of ground-based multi-coil electromagnetic induction (EMI) data with the airborne hyperspectral vegetation mapping of $1 \times 1 \mathrm{~m}$ pixels including sun-induced fluorescence $(\mathrm{F})$ to understand how subsurface structures drive above-surface plant performance. Hyperspectral data were processed to quantitative $\mathrm{F}$ and selected biophysical canopy maps, which are proxies for actual photosynthetic rates. These maps showed withinfield spatial patterns, which were attributed to paleo-river channels buried at around $1 \mathrm{~m}$ depth. The soil structures at specific depths were identified by quantitative EMI data inversions and confirmed by soil samples. Whereas the upper ploughing layer showed minor correlation to the plant data, the deeper subsoil carrying vital plant resources correlated substantially. Linking depth-specific soil information with plant performance data may greatly improve our understanding and the modeling of soil-vegetation-atmosphere exchange processes.
\end{abstract}

\title{
Plain Language Summary
}

Plants interact with soil. This is intuitive although we know little about the subsurface structure because we cannot see it. At first glance, all soil may look the same, yet, healthy plants can survive beside withered ones. We investigate the soil-plant interaction in an agricultural field situated in an area characterized by ancient (paleo-) river channels. These channels formed in sandy-gravelly material due to melting water after last glaciation, were then filled up with fine aeolien sediments, overlaid with soils up to $1 \mathrm{~m}$ thick, and are no longer visible at the surface. However, crops grow in meandering/braiding patterns that can be seen on satellite images, for example. To explain this, the subsurface structural geometry must be known. We combine ground-based electromagnetic induction data inversion results with airborne hyperspectral measurements to reveal the soil depths driving plant performance (photosynthetic activity and growth). Contrary to expectations, the deeper subsoil and not the ploughing layer controls plant performance at the investigated site. Plants above the buried paleo-river channels find nutrients and water, whereas the surrounding plants in gravelly soil suffer, especially during drought. These results improve our understanding of soil-plant interaction, which may improve soil-vegetation-atmosphere exchange process modeling and harvest predictability.

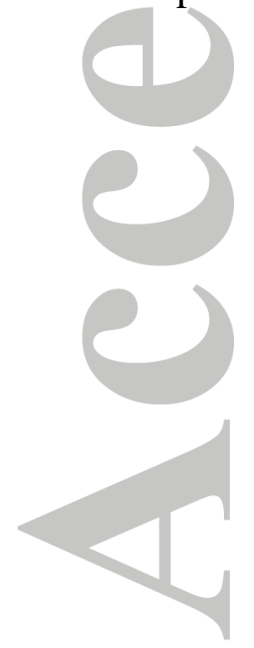

(C) 2018 American Geophysical Union. All rights reserved. 


\section{Introduction}

Photosynthetic carbon fixation and evaporation are major elements in the global carbon and water cycles. Great uncertainties still exist in determining water stored and supplied by the soil and in the efficiency with which plants access and use these soil water resources. Global soil moisture measurement platforms such as SMOS (soil moisture and ocean salinity, ESA) and SMAP (soil moisture active and passive, NASA) have greatly advanced our understanding in the spatio-temporal soil water dynamics. However, these satellite missions only observe soil moisture distributions of the upper $\sim 5 \mathrm{~cm}$ depth (Collow et al., 2012; Velpuri et al., 2016). In contrast, plants and crops generally develop deep and massive root systems especially in their later growth stage, thus accessing deep soil water to maintain photosynthesis and avoid drought when the surface soils have become dry. Winter wheat roots, for example, penetrate the soil in their five months vegetation period at depths of up to $2 \mathrm{~m}$ (Thorup-Kristensen et al., 2009). This means that plant and crop root systems reach water reservoirs that have remained undetected by recent satellite platforms.

To obtain information on subsurface structures (texture and layering), the inversion of geophysical data, such as ground-based multi-coil electromagnetic induction (EMI) can be used. EMI instruments house multiple coils with increasing separations in a rigid boom to simultaneously measure apparent electrical conductivity (ECa) values of increasing but overlapping depth ranges of investigation (DOI). In principle, inversions of multi-coil EMI data can disentangle the depth-specific electrical conductivity $(\sigma)$ layers. However, most EMI systems currently do not provide quantitative ECa values due to external influences; logger, cables, etc. (Gebbers et al., 2009). This hinders reliable EMI data inversion and only allows qualitative interpretations (Binley et al., 2015). To obtain reliable subsurface images, quantitative EMI data are needed (Mester et al., 2011; Minsley et al., 2012; Whalley et al., 2017). Measured ECa values can be calibrated, for example, using electrical resistivity tomography (Lavoué et al., 2010) or vertical electrical sounding data (Thiesson et al., 2014). Calibrated EMI data inversions have successfully obtained quantitative transect images (Mester et al., 2011) and field-scale soil structures (von Hebel et al., 2014) as well as soil water content changes during the growing season of wheat crops (Shanahan et al., 2015).

A geophysical link between soil and plant patterns is observed (Robinson et al., 2008) and investigated by correlating remotely sensed satellite-based leaf area index data and ground-based ECa values measured by a multi-coil EMI instrument (Rudolph et al., 2015). Increasing data correlations for increasing DOI's imply that the subsoil may be responsible for better crop development at water scarcity. Similar results were found by comparing crop development and spatial ECa patterns, where correlations were stronger in drier than in wetter growing seasons (Stadler et al., 2015). However, since ECa is a depth range average value (McNeill, 1980) these data cannot return depth-specific soil-plant interaction information.

Sun-induced fluorescence $(F)$ is directly related to photosynthetic rates and momentary plant performance. Passively, F can be measured at the leaf- and canopy-level using high performance commercial spectrometers such as FloxBox (JB Hyperspeed, Neuss, Germany) (Burkart et al., 2015) and at the field or regional level using airborne spectrometer such as HyPlant (Forschungszentrum Jülich, Germany, in cooperation with SPECIM-Spectral Imaging Ltd., Finnland) (Rascher et al., 2015). Recently, remote F measurements became widely available on satellite level. A few satellites already provide $\mathrm{F}$ data with a low spatial resolution, e.g., OCO-2 $\left(1.3 \times 2.25 \mathrm{~km}^{2}\right)$, GOSAT $(10 \mathrm{~km}$ diameter $)$, and GOME-2 $\left(80 \times 40 \mathrm{~km}^{2}\right)$ (Frankenberg et al., 2014; Joiner et al., 2013). Currently, ESA is implementing a high $(300 \mathrm{~m})$ resolution $\mathrm{F}$ satellite (Drusch et al., 2017). 
Fluorescence serves as an indicator for limited water availability and active fluorescence techniques are widely used to detect drought stress in plants (Ögren, 1990; Razavi et al., 2008; Takayama et al., 2011). Recently, passive F measurements have been used to detect drought-induced down regulation of photosynthesis (Ač et al., 2015; Damm et al., 2010; Rascher et al., 2009; Schickling et al., 2016).

The high resolution study presented here investigates how and at what depth subsurface structures control above-surface plant development and photosynthetic rates. We combine ground-based quantitative EMI data and their depth-specific inversion results with airborne plant performance data both of $1 \times 1 \mathrm{~m}$ pixels. This finds the interaction link of plants with the top- and the subsoil, which improves our understanding of the subsurface role on plant performance.

\section{Methods and data processing}

\subsection{Study site}

The study site ( 1.4 ha large agricultural field, termed F13, with south-western corner coordinate E: 320683, N: 5638407 in UTM Zone 32N) is close to Selhausen (Germany) and is part of the Transregional Collaborative Research Center on Patterns in the Soil-Vegetation-Atmosphere System (SFB-TR32) (Simmer et al., 2015). The Selhausen area is located within the southern part of the Lower Rhine Embayment close to the Rur River with a mean annual temperature of $10.2{ }^{\circ} \mathrm{C}$ and $715 \mathrm{~mm}$ annual precipitation (Ali et al., 2015).

In the Quaternary, river systems formed the landscape of the Selhausen area. F13 is located in the sand and gravel dominated upper terrace formed by the ancient Rur River in the Pleistocene (Weihermüller et al., 2007). Melting water after Weichselian glaciation formed breakaways and secondary channels that transported and deposited finer material in an approximately south-north running paleo-river channel system (Milbert, 2016) that was filled-up and buried with aeolien loess sediments (Rudolph et al., 2015).

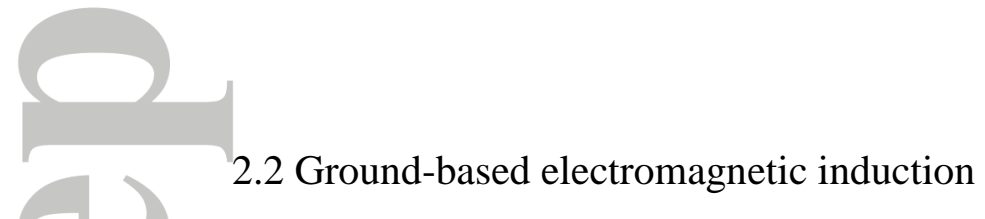

Multi-coil EMI instruments use one transmitter coil to generate a primary magnetic field while inducing eddy currents in the electrical conductive subsurface, which in turn generate a secondary magnetic field (Keller \& Frischknecht, 1966). The ratio of the secondary and primary magnetic field is related to the ground apparent electrical conductivity (Ward \& Hohmann, 1988).

The current research used a three- and a six-coil EMI instrument working respectively at $30 \mathrm{kHz}$ and $25 \mathrm{kHz}$ with vertical coplanar (VCP) and horizontal coplanar (HCP) coils. Figure 1 shows the coil specific local depth sensitivity curves. The crosses mark the DOI that has been defined by 0.75 and 1.5 times the coil separation (s) for VCP and HCP coils, respectively. The DOI indicated the depth range where the sensitivity accumulated to $70 \%$ from surface to depth (McNeill, 1980). The three VCP and six HCP sensitivities indicate that simultaneous measurements using both multi-coil EMI instruments cover shallow and deep DOI's with high resolution. Note that materials below the DOI contribute $\sim 30 \%$ to the 
measured ECa values and that quantitative inversions disentangle these overlapping contributions while returning depth-specific information.

The ground-based measurements were performed on 18/04/2016 with an average air temperature of $7.5^{\circ} \mathrm{C}$ and no precipitation on bare soil. Both EMI instruments were inserted into plastic sleds and warmed-up for $30 \mathrm{~min}$. A single frequency GPS system and a data logger were attached to a pole at $0.6 \mathrm{~m}$ and $1 \mathrm{~m}$ height, respectively, with the cables fixed to reduce measurement influences. During the measurements, ECa and GPS values were continuously sampled with $5 \mathrm{~Hz}$ and a quad-bike driving around $6-8 \mathrm{~km} / \mathrm{h}$ pulled the sleds. Apparent electrical conductivities of nine DOI's were recorded $\sim$ every $0.4 \mathrm{~m}$ along parallel tracks located around three meters apart.

Figure $2 \mathrm{a}$ exemplarily shows the recorded high resolution georeferenced ECa values for the HCPs180 coil configuration after outlier removal using a histogram filter (von Hebel et al., 2014). A nearest neighbor interpolation regridded the qualitative ECa values of each of the nine coil configurations to a map with a spatial resolution of $1 \mathrm{x} 1 \mathrm{~m}$ and 10609 regular nodes as shown in Figure $2 b$.

2.3 ECa calibration using multiple vertical electrical sounding data

To calibrate the large-scale ECa maps and obtain quantitative EMI data, we performed collocated EMI and VES measurements at three calibration locations (CL1 to CL3 shown in Figure 2a) that ideally cover the observed ECa ranges. At each CL, the EMI instruments recorded ECa values for around $30 \mathrm{sec}$ and their mean was used for calibration against predicted ECa values. To predict ECa values, VES data were acquired using the Schlumberger electrode array with outer electrode spacing between $0.5 \mathrm{~m}$ and $5 \mathrm{~m}$ to ensure shallow and deep apparent electrical resistivity $\left(\rho_{\mathrm{a}}=1 / \mathrm{ECa}\right)$ measurements. In total, $14 \rho_{\mathrm{a}}$ were recorded at each CL and subsequently inverted, see supporting information (SI), to obtain the vertical electrical conductivity distribution. These were inserted into the Maxwellbased full solution EMI forward model (Keller \& Frischknecht, 1966; Wait, 1951) along with the EMI instrument specifications. The predicted ECa values reflect an EMI measurement of pure subsurface without external influences. A linear regression of measured and predicted ECa values results in coil configuration specific calibration factors (see SI) that turn the qualitative ECa maps into calibrated data, which enable quantitative inversions. The HCPs97 map contained around $0.6 \%$ negative ECa values after calibration such that these data were excluded in the inversion and following analysis.

2.4 Inversion of quantitative large-scale EMI data

To obtain the depth-specific layered electrical conductivity distribution of field F13, the quantitative EMI data were inverted using the shuffled complex evolution (SCE) algorithm (Duan et al., 1993). The parallelized horizontally layered quasi-3D three-layer inversion scheme (von Hebel et al., 2014) ran on the JURECA supercomputer (Krause \& Thörnig, 2016). 
SCE combines deterministic and probabilistic strategies and treats the global optimization as an evolution process. Parameter combinations are evaluated, periodically shuffled, and newly sampled into subpopulations, i.e., complexes, to find strong and discard weak parameters. The Maxwell-based full solution EMI forward model modelled accurate EMI data and the misfit to real data was evaluated using the L1-norm without smoothing or damping. The L1-norm performs successful for EMI data inversion (Mester et al., 2011) and is most appropriate for abrupt layer changes (Loke et al., 2003), which is expected at the agricultural field F13.

The global optimization starts sampling from a parameter space given the nature of the EMI measurements and instrument specifications. The layer specific $\sigma$ values were optimized in-between double of the maximum and half of the minimum calibrated ECa values. The minimum layer thicknesses were set to $0.1 \mathrm{~m}$. The maximum first layer thickness was $0.35 \mathrm{~m}$ because of the ploughing depth. The maximum second layer thickness was 0.65 $\mathrm{m}$ corresponding to the peak sensitivity of HCPs180 (see Figure 1). To find the global minimum, SCE performed a maximum of 9000 function evaluations, 10 evolution loops, or stopped when the improvement was lesser than $1 \%$ compared to the previous evaluation for each of the $1 \times 1 \mathrm{~m}$ grid nodes.

The ground-based multi-coil EMI data processing, calibration, and inversion flow is summarized in the upper part of Figure 3. In the lower part, the airborne HyPlant data, processed to quantitative maps of normalized difference vegetation index and sun-induced fluorescence as described next, were correlated to the depth-specific $\sigma$ slices at three representative depths through the quasi-3D volume and to the ECa maps.

2.5 Airborne plant performance data

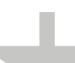

Illuminated photosynthetically active plants reflect, transmit and absorb light. The light re-emission is called fluorescence. Under optimal conditions about $80 \%$ of the absorbed light energy is used for photochemistry while the residual energy is lost as heat and dissipated as chlorophyll fluorescence emission. Therefore, $\mathrm{F}$ comes from the core of photosynthetic machinery and is directly linked with photosynthetic activity of the plant (Baker, 2008; Porcar-Castell et al., 2014).

The $\mathrm{F}$ spectrum is characterized by two broadband peaks centered in the red (685 $\mathrm{nm})$ and far-red (740 nm) spectral regions (Rossini et al., 2015), which is close to the atmospheric oxygen $\mathrm{O}_{2}-\mathrm{B}$ and $\mathrm{O}_{2}-\mathrm{A}$ absorption lines. To remotely sense the $\mathrm{F}$ spectrum, we used the high resolution airborne imaging spectrometer HyPlant. The sensor is a push-broom spectrometer that consists of two modules called DUAL and FLUO module (Rascher et al., 2015). The DUAL module measures radiance from $380 \mathrm{~nm}$ to $2500 \mathrm{~nm}$. The spectral resolution is $3 \mathrm{~nm}$ and $10 \mathrm{~nm}$ in the VIS/NIR and SWIR region, respectively. The highly accurate FLUO module measures radiance from $670 \mathrm{~nm}$ to $780 \mathrm{~nm}$ with $\pm 0.25 \mathrm{~nm}$ resolution. By this, the FLUO module resolves the spectral regions of the red and far-red fluorescence peaks with sub-nanometer resolution enabling the retrieval of $\mathrm{F}$ in the two oxygen absorption lines and some adjacent Fraunhofer lines. 
To obtain fluorescence data at $760 \mathrm{~nm}$ (F760) and at $687 \mathrm{~nm}$ (F687) using airborne measurements, we applied the improved Fraunhofer line depth (iFLD) approach (Wieneke et al., 2016), a modification of the 3FLD approach (Maier et al., 2003) further developed by (Damm et al., 2015). The iFLD method based on relating reflectance and F inside and outside the oxygen absorption bands using polynomial functions. During the retrieval, the F signal was separated from incoming to the sensor reflected by canopy and atmospheric particle radiation. Various atmospheric factors were approximated using atmospheric radiative transfer models such as MODTRAN-5 (Berk et al., 2004) and the MODTRAN interrogation technique introduced by Verhoef \& Bach $(2003 ; 2007)$. iFLD uses reference surfaces free of any $\mathrm{F}$ emission (e.g., bare soil) and retrieves a correction factor that allows adjusting the upward transmittance of atmosphere. After F retrieval a 2D digital (disk) filter that uses 2D convolution was applied to reduce noise.

The normalized difference vegetation index (NDVI) that quantifies green vegetation was obtained as final product of the DUAL spectrometer among further vegetation indices in three steps. First, pre-processing for the wavelength and radiometric calibration using CaliGeoPro (HyPlant manufacturer SPECIM, Finland), next the atmospheric correction to top-of-canopy reflectance data using the ATCOR software (Schläpfer et al., 2012), and finally NDVI was calculated by

$$
\mathrm{NDVI}=\frac{\mathrm{R}_{<795-810\rangle}-\mathrm{R}_{<665-680\rangle}}{\mathrm{R}_{<795-810>}+\mathrm{R}_{<665-680>}},
$$

where $\mathrm{R}_{<795-810>}$ and $\mathrm{R}_{<665-680>}$ are top-of-canopy reflectance values averaged between $795 \mathrm{~nm}$ and $810 \mathrm{~nm}$ and $665 \mathrm{~nm}$ and $680 \mathrm{~nm}$, respectively.

The 1x1 m hyperspectral data were collected during a $600 \mathrm{~m}$ height flight overpass on 30/6/2015 between 14:40 and 15:00 local time after solar noon with clear sky and winter wheat at F13. Both May and June were relatively hot $\left(19^{\circ} \mathrm{C}\right.$ and $23^{\circ} \mathrm{C}$ mean temperature) and dry $(25 \mathrm{~mm}$ and $31 \mathrm{~mm}$ cumulative precipitation) such that drought stress was expected.

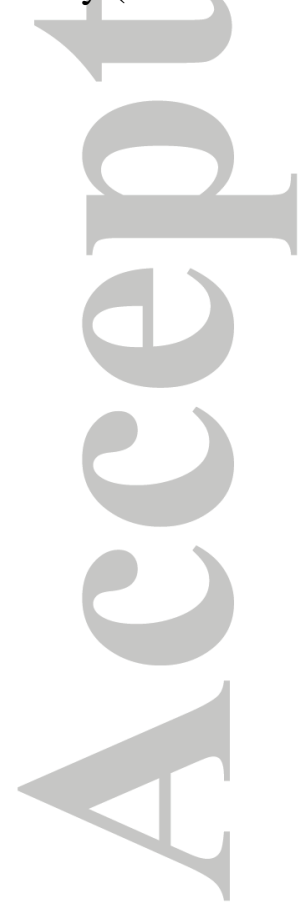




\section{Combined topsoil/subsoil and plant performance analysis}

Figure 4a shows the ground-based quantitative ECa maps for the nine different EMI coil configurations obtained after VES-based calibration and Figure $4 \mathrm{~b}$ presents three slices through the quasi-3D volume obtained after the three-layer EMI data inversion. Soil cores were taken at locations $\mathrm{BH} 1-6$ and $\mathrm{BH} 7$ to validate the inverted interface depths.

Figure 4c displays the quantitative NDVI, F687, and F760 maps. Here, the northsouth (N-S) directed paleo-river channel structure clearly showed up with higher amplitudes in the plant performance data. High NDVI values (approximately 0.6 to 0.9 ) correspond to dense green vegetation, while senescing crops usually show moderate values (approximately 0.2 to 0.5 ) (Sultana et al., 2014). The values of field F13 indicate that the winter wheat reached senesce earlier at the coarse textured soil, which result in lower fluorescence. Simultaneously, the wheat growing above the N-S directed paleo-river channel was still green (NDVI 0.75) and photosynthetically active, which resulted in increased F687 and F760 values.

A similar N-S directed pattern was observed in all calibrated ECa maps presented in Figure 4a. The pattern was most visible for the deeper DOI's, whereas for the shallower DOI's additional patterns seemed to be superposed. Using ECa, the specific depth causing the plant pattern cannot be determined. Instead, quantitative quasi-3D inversions are necessary. Figure $4 \mathrm{~b}$ shows three representative $\sigma$ depth slices at $\mathrm{z}=0.15 \mathrm{~m}, 0.50 \mathrm{~m}$, and $1 \mathrm{~m}$. The ploughing layer $(\mathrm{z}=0.15 \mathrm{~m})$ showed a relatively homogeneous $\sigma$ distribution and no explanation of the observed plant patterns. In the slice at $1 \mathrm{~m}$ depth, the $\mathrm{N}-\mathrm{S}$ directed structure was clearly visible by larger $\sigma$ values $(\sim 20 \mathrm{mS} / \mathrm{m})$ compared to the low $(\sim 5 \mathrm{mS} / \mathrm{m})$ surrounding $\sigma$ values. At the intermediate slice $(\mathrm{z}=0.50 \mathrm{~m})$, increased $\sigma$ values $(\sim 10 \mathrm{mS} / \mathrm{m})$ were present in the south.

At locations BH1-6, six soil cores were taken with $1 \mathrm{~m}$ distance in N-S direction. These showed a ploughing layer of $\sim 0.3 \mathrm{~m}$ overlying a clayey-silt layer until the top of the clay-rich paleo-river channel at (mean \pm std) $0.7 \mathrm{~m} \pm 0.2 \mathrm{~m}$ depth. The samples confirmed the EMI inversions, where the mean inverted paleo-river channel top was at $0.7 \mathrm{~m} \pm 0.3 \mathrm{~m}$ depth for the six locations (see SI). The soil sampled at borehole BH7 consisted of low cohesive gravelly soil.

Since the buried paleo-river channel carries fine textured soil and the maps of abovesurface plant performance (Figure 4c) showed the paleo-river channel pattern, the crops likely access nutrient and water reservoirs in the deeper subsoil. The paleo-river channel buried at $\sim 1 \mathrm{~m}$ depth as identified by the EMI inversion results inherently has a larger water holding capacity resulting in more plant available water as compared to the surrounding coarse material.

To quantify the top- and subsoil-plant interaction, we calculate the Pearson correlation coefficient (r) between the subsurface EMI and above-surface HyPlant data that showed an approximate linear relation (see SI). Figure 4d shows the correlation of ECa with NDVI, F687, and F760. The increasing $r(0.5<r<0.79)$ with increasing DOI indicates that the deeper subsoil is increasingly responsible for crop performance. However, specific depths cannot be distilled using ECa maps.

Correlations between the depth-specific $\sigma$ obtained by EMI inversion with NDVI, F687, and F760 (Figure 4e) show that the ploughing layer played no role, since $r<0.35$. 
Intermediate $r$ values were obtained for the intermediate layer. The $r$ values up to 0.72 for the deeper subsoil $(\mathrm{z} \sim 1 \mathrm{~m})$ show that the material at this depth was responsible for the increased crop performance. Although the EMI and F data were not measured at the same time, the ground truth soil cores confirmed the subsoil structures that interact with the crops.

Whereas relatively large $\mathrm{r}$ values were obtained for the VCPs32 coil configuration with small DOI $(0-0.2 \mathrm{~m})$, the depth-specific $\sigma$ values at $0.15 \mathrm{~m}$ showed very low correlation. This is due to the fact that depths below the DOI contribute $~ 30 \%$ to the measured ECa (see also Figure 1). Especially when the upper layer is relatively homogeneous, electrical conductive material beyond the DOI can strongly contribute to ECa as shown here.

Care should be taken when directly correlating ECa and plant data, because ECa is a depth range average value reaching beyond the usually assumed DOI. To accurately determine the depths at which the ECa patterns originate from, quantitative EMI data obtained by proper calibration needs to be inverted using an accurate EMI forward model as introduced by von Hebel et al. (2014). Here, correlating hyperspectral plant data and depthspecific quasi-3D $\sigma$ slices disentangled the top- and subsoil-plant interaction.

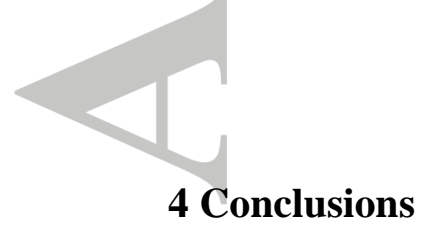

We investigated the effect of subsurface soil properties on plant performance by combining ground-based geophysical and airborne plant data measured in dry states over an area of 1.4 ha with $1 \times 1 \mathrm{~m}$ pixels. Using quantitative multi-coil EMI data inversions, we obtained depth-specific soil information that was confirmed by soil coring. This was possible after ECa calibration based on VES data of three locations covering the large-scale ECa range.

A significant correlation of the inverted depth-specific information and the airborne plant data show that the deeper subsoil, a paleo-river channel buried at around $1 \mathrm{~m}$ depth carrying loess sediments, drives plant performance. This is most likely due to the large water/nutrient pool. These vital plant resources increase photosynthetic activity over that of the plants growing above the surrounding coarser soil. Since ECa values cannot be related to specific depths, quantitative multi-coil EMI data inversions are needed to link depth-specific soil to plant interaction.

Distinct sun-induced fluorescence patterns were created by structural differences and therefore water-holding capacity differences in soil at depths of $1 \mathrm{~m}$, which means that $\mathrm{F}$ data can contain soil moisture information at depth. Together with quantitative EMI data inversions, this information can be used to reduce existing uncertainties in assessing the efficiency with which plants access and use the soil water/nutrient resources. This new approach will help to inform and improve soil-plant-atmosphere models for root water uptake processes as well as harvest predictability tools.

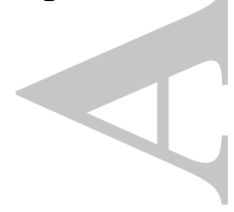




\section{Acknowledgements:}

We thank AE Valeriy Ivanov as well as Andrew Binley and an anonymous Reviewer for significantly improving the manuscript. We acknowledge SFB/TR32 'Pattern in SoilVegetation-Atmosphere Systems: Monitoring, Modelling and Data Assimilation' funded by DFG. We thank ESA funding the airborne fluorescence measurements, Contract 4000107143/12/NL/FF/If-CCN3. We thank TERENO and ACROSS, as well as the Jülich supercomputer center. Data repository is the TR32 database http://www.tr32db.uni-koeln.de.

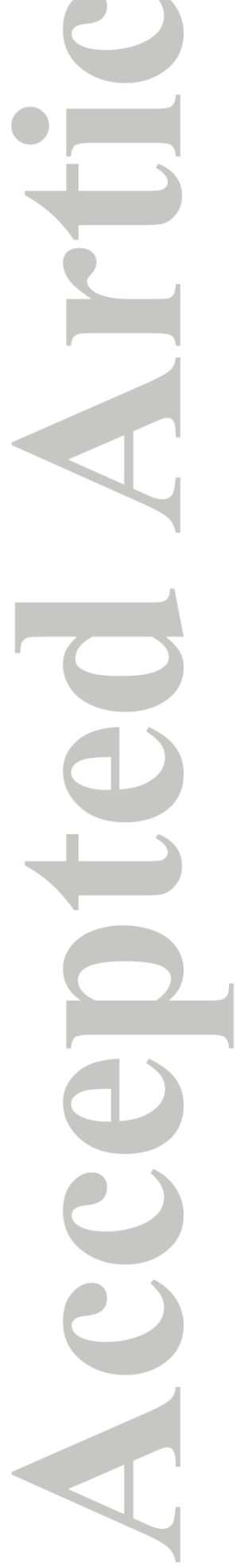




\section{REFERENCES}

Ač, A., Malenovský, Z., Olejníčková, J., Gallé, A., Rascher, U., \& Mohammed, G. (2015), Meta-analysis assessing potential of steady-state chlorophyll fluorescence for remote sensing detection of plant water, temperature and nitrogen stress, Remote Sensing of Environment, 168, 420-436.

Ali, M., Montzka, C., Stadler, A., Menz, G., Thonfeld, F., \& Vereecken, H. (2015), Estimation and Validation of RapidEye-Based Time-Series of Leaf Area Index for Winter Wheat in the Rur Catchment (Germany), Remote Sensing, 7(3), 2808-2831.

Baker, N. R. (2008), Chlorophyll Fluorescence: A Probe of Photosynthesis In Vivo, Annual Review of Plant Biology, 59(ISO 11277), 89-113.

Berk, A., Cooley, T. W., Anderson, G. P., Acharya, P. K., Bernstein, L. S., Muratov, L., et al. (2004),

MODTRAN5: a reformulated atmospheric band model with auxiliary species and practical multiple scattering options, paper presented at Remote Sensing, SPIE, Maspalomas, Canary Islands, Spain.

Binley, A., Hubbard, S. S., Huisman, J. A., Revil, A., Robinson, D. A., Singha, K., \& Slater, L. D. (2015), The emergence of hydrogeophysics for improved understanding of subsurface processes over multiple scales, Water Resources Research, 51(6), 3837-3866.

Burkart, A., Schickling, A., Mateo, M. P. C., Wrobel, T. J., Rossini, M., Cogliati, S., et al. (2015), A Method for Uncertainty Assessment of Passive Sun-Induced Chlorophyll Fluorescence Retrieval Using an Infrared Reference Light, IEEE Sensors Journal, 15(8), 4603-4611.

Collow, T. W., Robock, A., Basara, J. B., \& Illston, B. G. (2012), Evaluation of SMOS retrievals of soil moisture over the central United States with currently available in situ observations, Journal of Geophysical Research: Atmospheres, 117(D09113).

Damm, A., Elbers, J., Erler, A., Gioli, B., Hamdi, K., Hutjes, R., et al. (2010), Remote sensing of sun-induced fluorescence to improve modeling of diurnal courses of gross primary production (GPP), Global Change Biology, 16(ISO 11277), 171-186.

Damm, A., Guanter, L., Paul-Limoges, E., van der Tol, C., Hueni, A., Buchmann, N., et al. (2015), Far-red suninduced chlorophyll fluorescence shows ecosystem-specific relationships to gross primary production: An assessment based on observational and modeling approaches, Remote Sensing of Environment, 166, 91-105. Drusch, M., Moreno, J., Del Bello, U., Franco, R., Goulas, Y., Huth, A., et al. (2017), The FLuorescence EXplorer Mission Concept-ESA's Earth Explorer 8, Ieee Transactions on Geoscience and Remote Sensing, 55(3), 1273-1284.

Duan, Q. Y., Gupta, V. K., \& Sorooshian, S. (1993), Suffled complex evolution apporach for effective and efficient global minimization, Journal of Optimization Theory and Applications, 76(3), 501-521.

Ekinci, Y. L., \& Demirci, A. (2008), A Damped Least-Squares Inversion Program for the Interpretation of Schlumberger Sounding Curves, Journal of Applied Sciences, 8(22), 4070-4078.

Frankenberg, C., O'Dell, C., Berry, J., Guanter, L., Joiner, J., Kohler, P., et al. (2014), Prospects for chlorophyll fluorescence remote sensing from the Orbiting Carbon Observatory-2, Remote Sensing of Environment, 147, 112.

Gebbers, R., Lueck, E., Dabas, M., \& Domsch, H. (2009), Comparison of instruments for geoelectrical soil mapping at the field scale, Near Surface Geophysics, 7(3), 179-190.

Joiner, J., Guanter, L., Lindstrot, R., Voigt, M., Vasilkov, A. P., Middleton, E. M., et al. (2013), Global monitoring of terrestrial chlorophyll fluorescence from moderate-spectral-resolution near-infrared satellite measurements: methodology, simulations, and application to GOME-2, Atmospheric Measurement Techniques, 6(10), 2803-2823.

Keller, G. V., \& Frischknecht, F. C. (1966), Electrical methods of geophysical prospecting, International Series of Monographs in Electromagnetic Waves, Pergamon Press, Oxford, New York, 10.

Krause, D., \& Thörnig, P. (2016), JURECA: General-purpose supercomputer at Jülich Supercomputing Centre, Journal of large-scale research facilities, 2, A62.

Lavoué, F., van der Kruk, J., Rings, J., Andre, F., Moghadas, D., Huisman, J. A., et al. (2010), Electromagnetic induction calibration using apparent electrical conductivity modelling based on electrical resistivity tomography, Near Surface Geophysics, 8(6), 553-561.

Loke, M. H., Acworth, I., \& Dahlin, T. (2003), A comparison of smooth and blocky inversion methods in 2D electrical imaging surveys, Exploration Geophysics, 34(3), 182-187.

Maier, S. W., Günther, K. P., \& Stellmes, M. (2003), Sun-Induced Fluorescence: A New Tool for Precision Farming, in Digital Imaging and Spectral Techniques: Applications to Precision Agriculture and Crop Physiology, edited by J. Schepers \& VanToai, T., pp. 209-222, American Society of Agronomy, Crop Science Society of America, and Soil Science Society of America, Madison, WI.

McNeill, J. D. (1980), Electromagnetic terrain conductivity measurement at low induction numbers, Technical Note TN-6. Geonics Ltd., Mississauga, ON, Canada. 
Mester, A., van der Kruk, J., Zimmermann, E., \& Vereecken, H. (2011), Quantitative two-layer conductivity inversion of multi-configuration electromagnetic induction measurements, Vadose Zone Journal, 10(4), 13191330 .

Milbert, G. (2016), Email Altersbestimmung von verschütteten Flußstrukturen Selhausen, Email sent by Milbert, G. (Geologischer Dienst Nordrhein-Westfalen) to van der Kruk, J., 03/02/2016.

Minsley, B. J., Smith, B. D., Hammack, R., Sams, J. I., \& Veloski, G. (2012), Calibration and filtering strategies for frequency domain electromagnetic data, Journal of Applied Geophysics, 80, 56-66.

Ögren, E. (1990), Evaluation of Chlorophyll Fluorescence as a Probe for Drought Stress in Willow Leaves, Plant Physiology, 93(4), 1280-1285.

Porcar-Castell, A., Tyystjärvi, E., Atherton, J., van der Tol, C., Flexas, J., Pfündel, E. E., et al (2014), Linking chlorophyll a fluorescence to photosynthesis for remote sensing applications: mechanisms and challenges, Journal of Experimental Botany, 65(15), 4065-4095.

Rascher, U., Agati, G., Alonso, L., Cecchi, G., Champagne, S., Colombo, R., et al. (2009), CEFLES2: the remote sensing component to quantify photosynthetic efficiency from the leaf to the region by measuring suninduced fluorescence in the oxygen absorption bands, Biogeosciences, 6(ISO 11277), 1181-1198.

Rascher, U., Alonso, L., Burkart, A., Cilia, C., Cogliati, S., Colombo, R., et al. (2015), Sun-induced fluorescence - a new probe of photosynthesis: First maps from the imaging spectrometer HyPlant, Global Change Biology, 21(12), 4673-4684.

Razavi, F., Pollet, B., Steppe, K., \& van Labeke, M. C. (2008), Chlorophyll fluorescence as a tool for evaluation of drought stress in strawberry, Photosynthetica, 46(4), 631-633.

Robinson, D. A., Abdu, H., Jones, S. B., Seyfried, M., Lebron, I., \& Knight, R. (2008), Eco-Geophysical Imaging of Watershed-Scale Soil Patterns Links with Plant Community Spatial Patterns, Vadose Zone Journal, 7(4), 1132-1138.

Rossini, M., Nedbal, L., Guanter, L., Ač, A., Alonso, L., Burkart, A., et al. (2015), Red and far red Sun-induced chlorophyll fluorescence as a measure of plant photosynthesis, Geophysical Research Letters, 42(6), 1632-1639. Rudolph, S., van der Kruk, J., von Hebel, C., Ali, M., Herbst, M., Montzka, C., et al. (2015), Linking satellite derived LAI patterns with subsoil heterogeneity using large-scale ground-based electromagnetic induction measurements, Geoderma, 241, 262-271.

Schickling, A., Matveeva, M., Damm, A., Schween, J. H., Wahner, A., Graf, A., et al. (2016), Combining SunInduced Chlorophyll Fluorescence and Photochemical Reflectance Index Improves Diurnal Modeling of Gross Primary Productivity, Remote Sensing, 8(7), 18.

Schläpfer, D., Richter, R., \& Kellenberger, T. (2012), Aspects of atmospheric and topographic correction of high spatial resolution imagery, paper presented at 2012 IEEE International Geoscience and Remote Sensing Symposium, 22-27 July 2012.

Shanahan, P. W., Binley, A., Whalley, W. R., \& Watts, C. W. (2015), The Use of Electromagnetic Induction to Monitor Changes in Soil Moisture Profiles beneath Different Wheat Genotypes, Soil Sci. Soc. Am. J., 79(2),459466.

Simmer, C., Thiele-Eich, I., Masbou, M., Amelung, W., Bogena, H. R., Crewell, S., et al. (2015), Monitoring and Modeling the Terrestrial System from Pores to Catchments: The Transregional Collaborative Research Center on Patterns in the Soil-Vegetation-Atmosphere System, Bulletin of the American Meteorological Society, 96(10), 1765-1787.

Stadler, A., Rudolph, S., Kupisch, M., Langensiepen, M., van der Kruk, J., \& Ewert, F. (2015), Quantifying the effects of soil variability on crop growth using apparent soil electrical conductivity measurements, Eur. J. Agron., 64, 8-20.

Sultana, S. R., Ali, A., Ahmad, A., Mubeen, M., Zia-Ul-Haq, M., Ahmad, S., et al. (2014), Normalized Difference Vegetation Index as a Tool for Wheat Yield Estimation: A Case Study from Faisalabad, Pakistan, The Scientific World Journal, 2014, 725326.

Takayama, K., Nishina, H., Iyoki, S., Arima, S., Hatou, K., Ueka, Y., \& Miyoshi, Y. (2011), Early detection of drought stress in tomato plants with chlorophyll fluorescence imaging-practical application of the speaking plant approach in a greenhouse-, IFAC Proceedings Volumes, 44(1), 1785-1790.

Thiesson, J., Kessouri, P., Schamper, C., \& Tabbagh, A. (2014), Calibration of frequency-domain electromagnetic devices used in near-surface surveying, Near Surface Geophysics, 12(4), 481-491. Thorup-Kristensen, K., Salmerón Cortasa, M., \& Loges, R. (2009), Winter wheat roots grow twice as deep as spring wheat roots, is this important for $\mathrm{N}$ uptake and $\mathrm{N}$ leaching losses?, Plant and Soil, 322(1), 101-114. Velpuri, N. M., Senay, G. B., \& Morisette, J. T. (2016), Evaluating New SMAP Soil Moisture for Drought Monitoring in the Rangelands of the US High Plains, Rangelands, 38(4), 183-190.

Verhoef, W., \& Bach, H. (2003), Simulation of hyperspectral and directional radiance images using coupled biophysical and atmospheric radiative transfer models, Remote Sensing of Environment, 87(1), 23-41. 
Verhoef, W., \& Bach, H. (2007), Coupled soil-leaf-canopy and atmosphere radiative transfer modeling to simulate hyperspectral multi-angular surface reflectance and TOA radiance data, Remote Sensing of Environment, 109(2), 166-182.

von Hebel, C., Rudolph, S., Mester, A., Huisman, J. A., Kumbhar, P., Vereecken, H., \& van der Kruk, J. (2014), Three-dimensional imaging of subsurface structural patterns using quantitative large-scale multiconfiguration electromagnetic induction data, Water Resources Research, 50, 2732-2748.

Wait, J. R. (1951), The magnetic diploe over the horizontally stratified earth, Canadian Journal of Physics, 29(6), 577-592.

Ward, S., \& Hohmann, G. (1988), Electromagnetic Theory for Geophysical Applications, in Electromagnetic Methods in Applied Geophysics, edited by M. N. Nabighian, pp. 130-311, Soceity of Exploration Geophysicists, United States of America.

Weihermüller, L., Huisman, J. A., Lambot, S., Herbst, M., \& Vereecken, H. (2007), Mapping the spatial variation of soil water content at the field scale with different ground penetrating radar techniques, Journal of Hydrology, 340(3-4), 205-216.

Whalley, W. R., Binley, A., Watts, C. W., Shanahan, P., Dodd, I. C., Ober, E. S., et al. (2017), Methods to estimate changes in soil water for phenotyping root activity in the field, Plant and Soil, 415(1), 407-422. Wieneke, S., Ahrends, H., Damm, A., Pinto, F., Stadler, A., Rossini, M., \& Rascher, U. (2016), Airborne based spectroscopy of red and far-red sun-induced chlorophyll fluorescence: Implications for improved estimates of gross primary productivity, Remote Sensing of Environment, 184, 654-667.
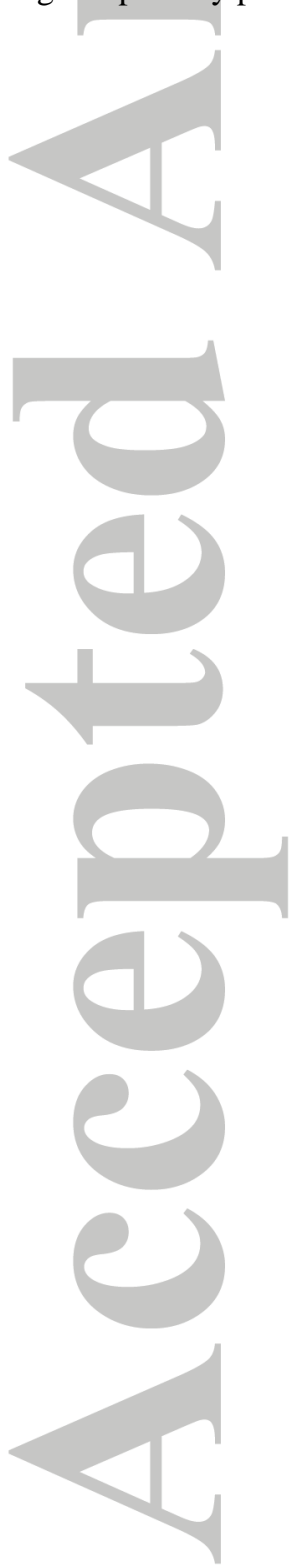
(a) VCP

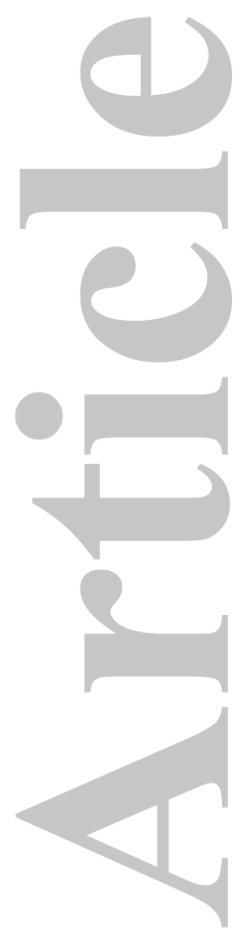

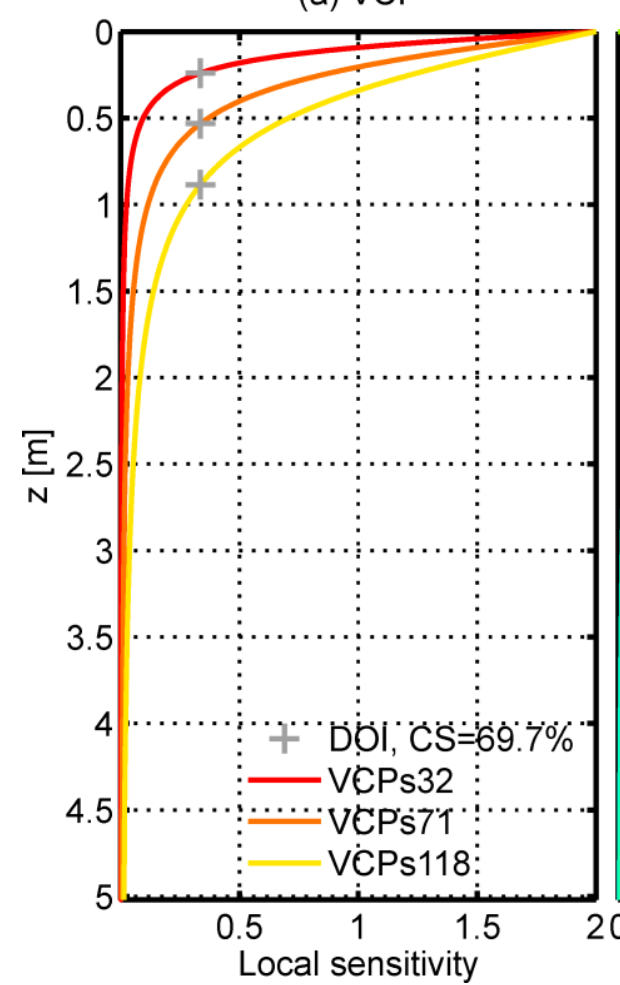

(b) HCP

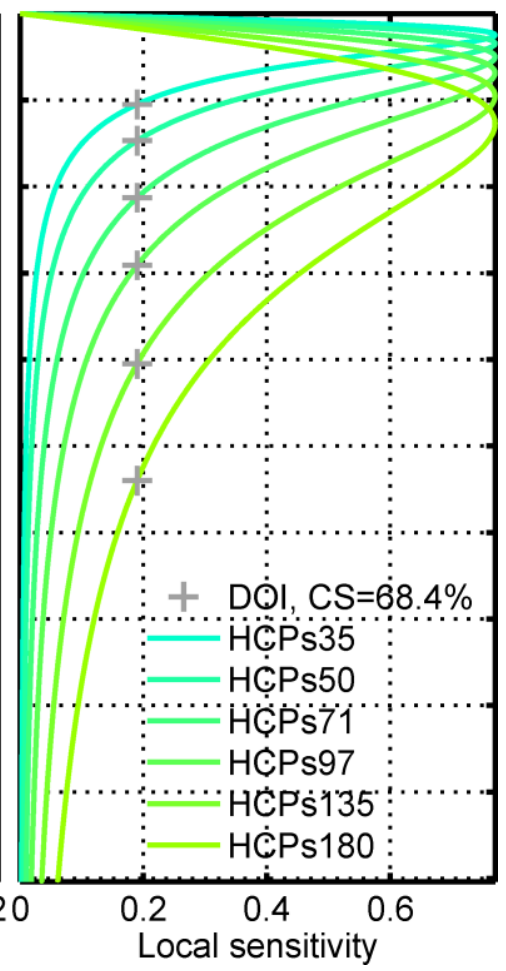

Figure 1: Local depth sensitivities of (a) the three-coil CMD-MiniExplorer used with vertical coplanar (VCP) coils with separations (s) of 32,71 , and $118 \mathrm{~cm}$ and (b) the six-coil CMD-MiniExplorer Special Edition used with horizontal coplanar (HCP) coils with $\mathrm{s}=35,50,71,97,135$, and $180 \mathrm{~cm}$ both manufactured by GF-Instruments (Brno, Czech Republic). The crosses indicate the depth range of investigation (DOI) where the cumulative sensitivity (CS) is $\sim 70 \%$. Note that deeper material contribute to ECa. 
(a) Filtered and smoothed ECa recordings

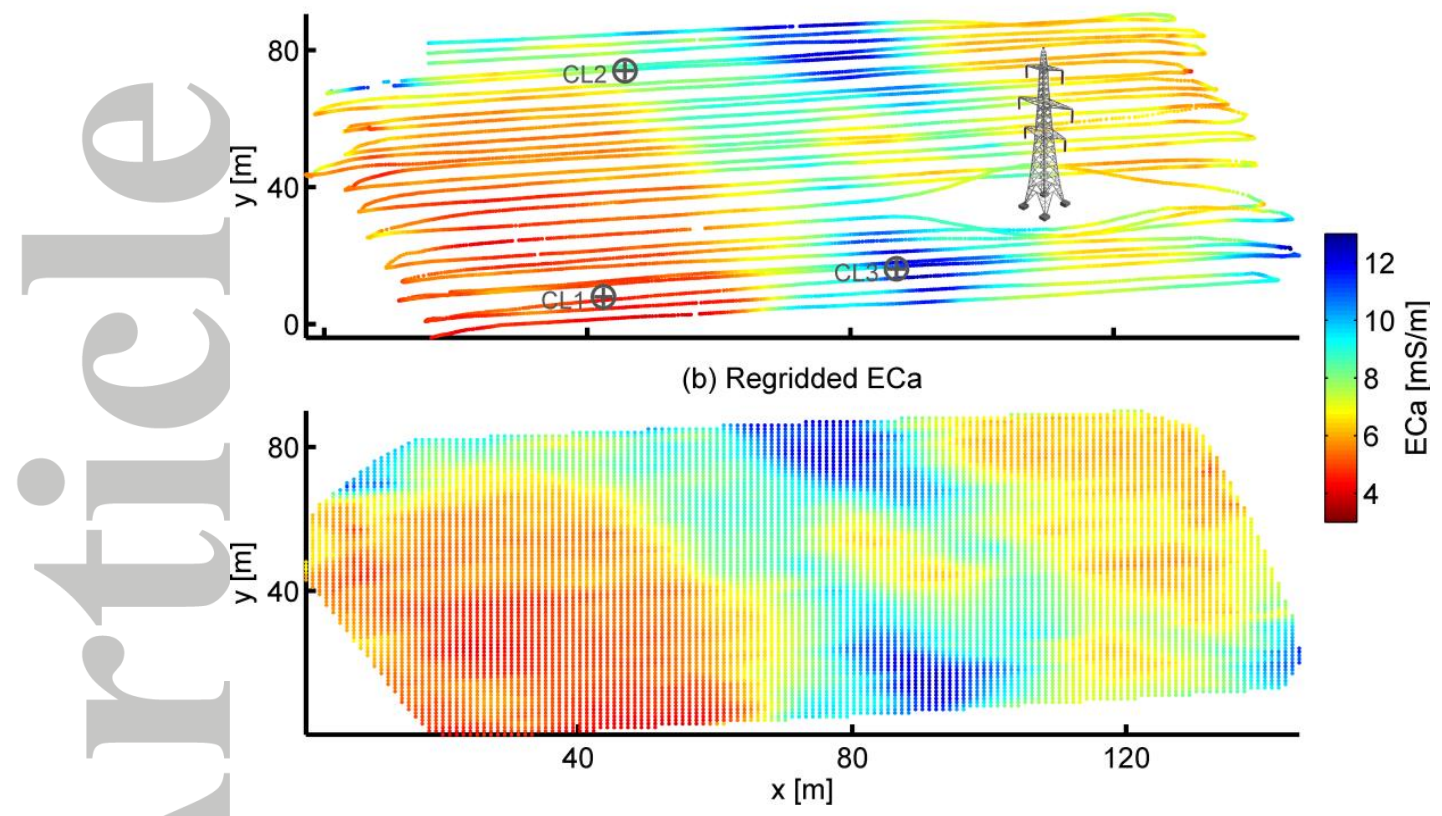

Figure 2: (a) Filtered and smoothed ECa values of the HCPs180 coil configuration. Three calibration locations (CL) were selected in the field during the EMI measurements. At each CL, EMI measurements and vertical electrical soundings (VES) using a Lippmann 4point light 10W (Lippmann Geophysikalische Messgeräte, Schaufling, Germany) were performed. Since the ECa range of F13 is covered, these collocated measurements calibrated the large-scale ECa maps. (b) Regridded qualitative ECa map with 1x1 m nodes.

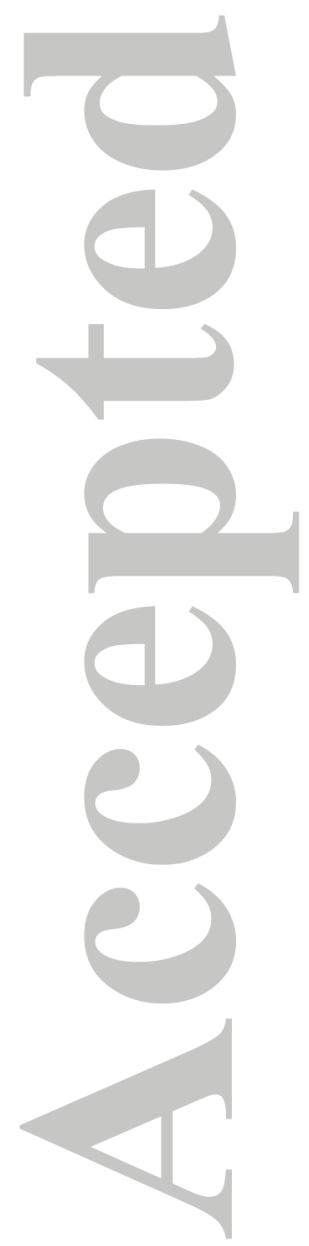



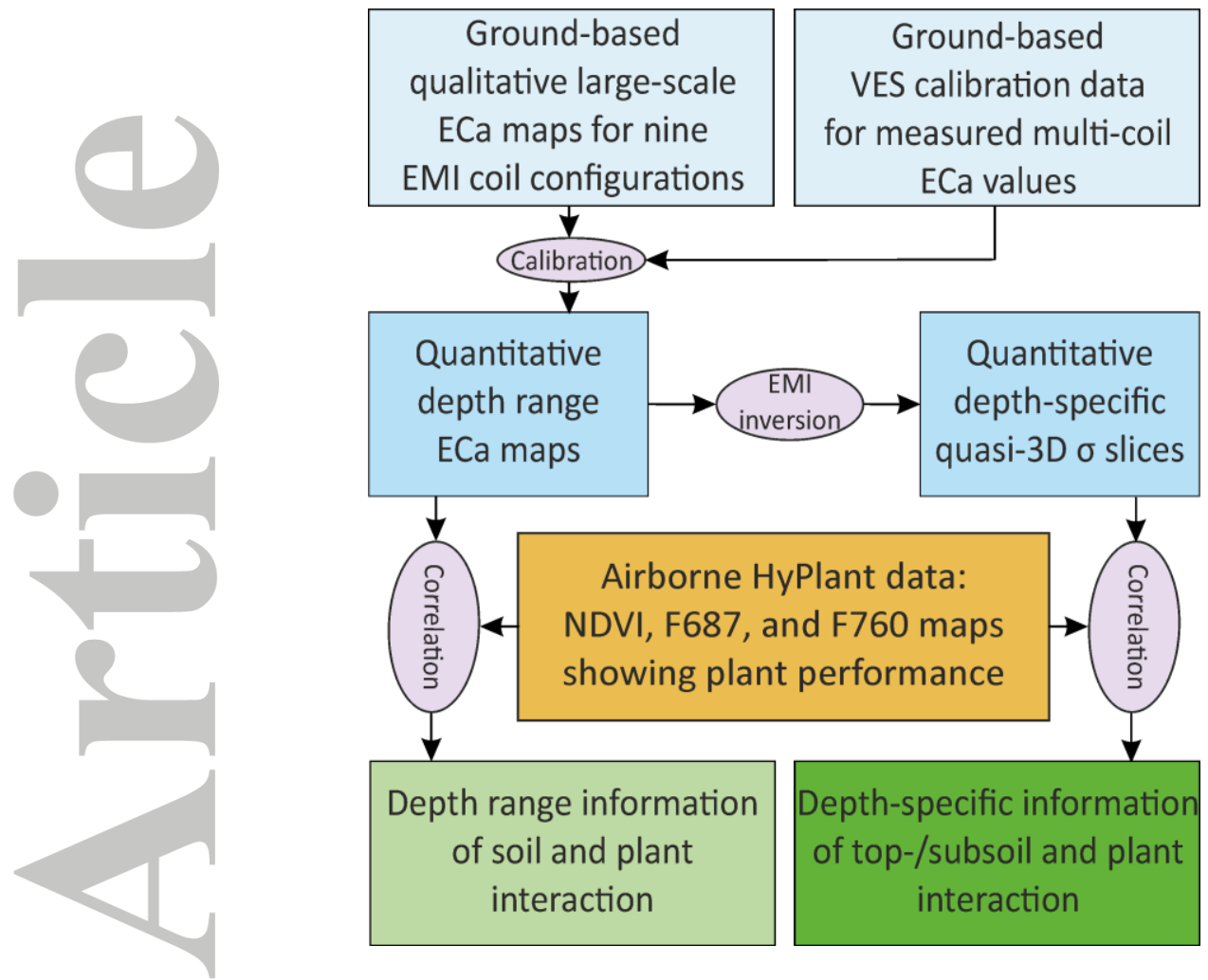

Figure 3: Overview of understanding soil-plant interaction by combining the ground-based subsurface and airborne plant data. The measured multi-coil electromagnetic induction (EMI) data were calibrated based on vertical electrical sounding (VES) data. The obtained quantitative EMI data were inverted to obtain quantitative depthspecific quasi-3D electrical conductivity slices, which allow investigating the depth-specific topsoil/subsoil role on plant performance. The depth range averaged ECa maps were also correlated to the airborne HyPlant data for comparison. 


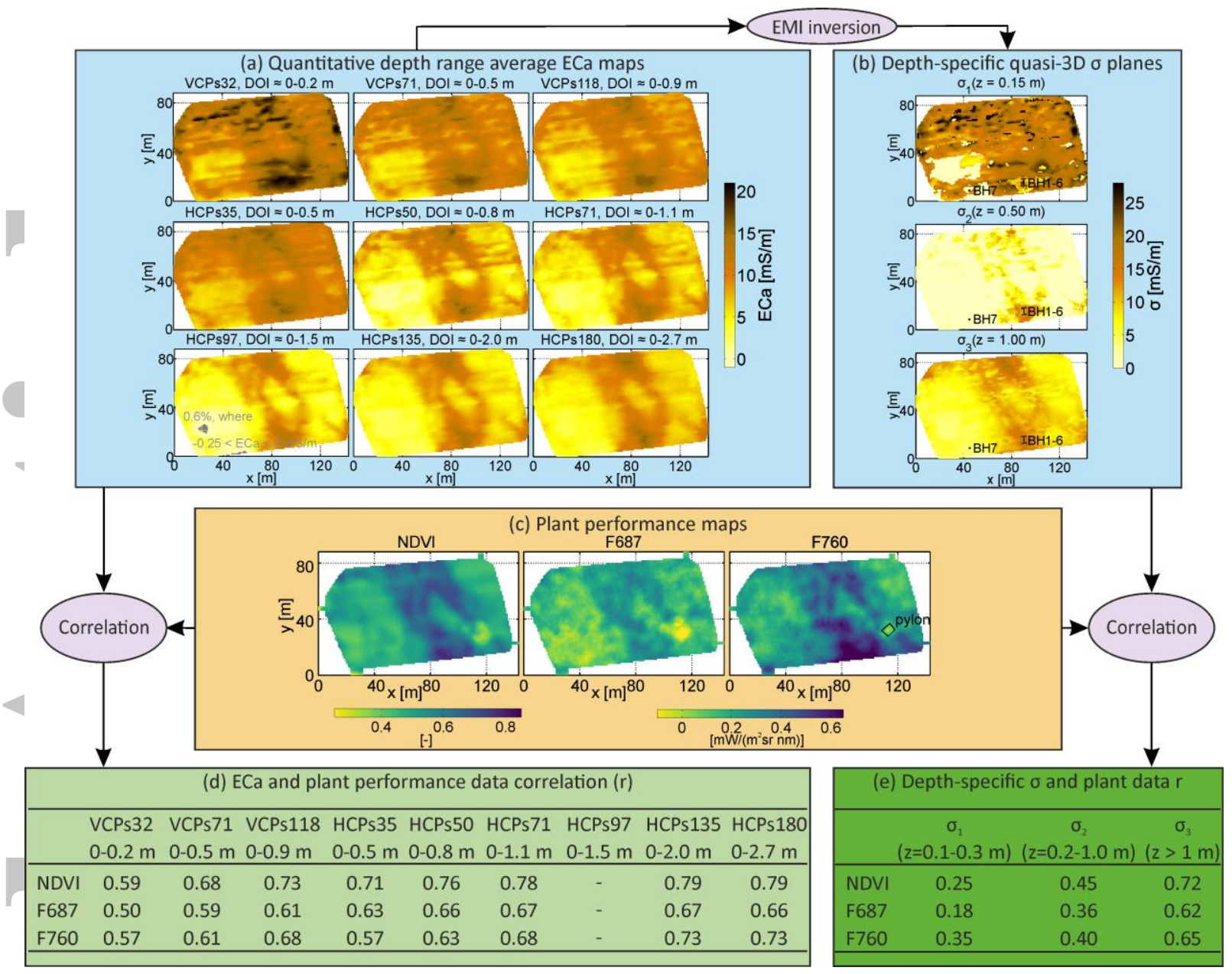

Figure 4: Investigating topsoil/subsoil-plant interaction by combining ground-based EMI, airborne greenness (NDVI), and fluorescence data (F687, F760). (a) Quantitative ECa maps for VCP coils (top row) and HCP coils (middle and lower row) with increasing DOI. B) Depth-specific slices through the inverted quasi-3D electrical conductivity model for the ploughing layer at $0.15 \mathrm{~m}$, at $0.5 \mathrm{~m}$ depth, where the soil material changed, and at $1 \mathrm{~m}$ depth, where the paleo-river channel is clearly visible. Six soil samples at BH1-6 showed a mean plough horizon of $0.3 \mathrm{~m}$ depth, a clayey-silt layer until $0.7 \mathrm{~m} \pm 0.2 \mathrm{~m}$ depth (where the mean inverted depth \pm std was $0.7 \mathrm{~m} \pm 0.3 \mathrm{~m}$ ), and a clay-rich zone underneath. At BH7, gravelly soil with low cohesion to the Pürkhauer sampling device was present. C) Airborne NDVI, F687, and F760 maps that show the paleo-river channel pattern. In D) and E) the correlation coefficients ( $r$ ) of plant performance with ECa (left branch) and inverted $\sigma$ (right branch) are respectively calculated. The increasing $r$ with increasing DOI shown in panel $D$ indicates that deeper subsoil was responsible for plant performance. Panel $E$ evidently shows that the deeper soil $\sigma_{3}(z>1 \mathrm{~m})$ was responsible for plant performance $(r$ $>0.62)$, whereas the ploughing layer played no role $(\mathbf{r}<0.35)$. 